\title{
INTERNATIONAL PERSPECTIVES ON INQUIRY IN SECONDARY SCIENCE
}

\author{
Michael Svec \\ Furman University, USA \\ Neil Hutton \\ University of Sunderland, United Kingdom \\ Danuše Nezvalová \\ Palacky University, Czech Republic
}

\begin{abstract}
Inquiry, as both an instructional method and as a curriculum goal, is a common theme in science education reforms in both North America and Europe. This paper will initiate a discussion on the definitions and practice of inquiry in three countries; United Kingdom, Czech Republic and United States. Each national context will describe how inquiry is defined in both the relevant curriculums and in the academic publications. The assumptions will be identified that influenced the understanding of inquiry and the relationship to the science process skills, science literacy and the nature of science. The practiced curriculum will then be presented demonstrating how inquiry as both instruction and curriculum is practiced. National conditions and factors that encourage or impede inquiry will be discussed. A summary will examine common themes across the different national contexts.
\end{abstract}

Key words: inquiry, national context, secondary science.

\section{Introduction}

"Inquiry" has become an almost ubiquitous theme in science education reforms in the United States and increasingly around the world. Abd-El-Khalick et al (2004) noted that inquiry in science education "is one of the few overarching themes that cut across precollege science curricula in countries around the globe" (p. 399). Such an international focus brings with the possibility of discourse between science educators on how inquiry is defined and practiced within their national contexts. The prominence of inquiry in science education highlights the need to understand what is inquiry and what are the challenges of implementation.

In 2001 a symposium (Abd-El-Khalick et al, 2001) was conducted at an international science education meeting that explored issues associated with the enactment of inquiry from several different science educators representing Lebanon, United States, Israel, Venezuelan, Australia, and Taiwan. The paper "Inquiry in Science Education: International Perspectives" (Abd-El-Khalick et al, 2004) emerged from that symposium.

This paper explores similar themes and initiates a discussion on the definitions and practice of inquiry in three countries; United Kingdom, Czech Republic and United States. Discourse from different perspectives improves collaboration between science educators who are seeking to reform science education in their national contexts. Each national context will describe how inquiry is defined in both the relevant curriculums and in the academic publications. The practiced curriculum will then be presented demonstrating how inquiry as both instruction and curriculum is practiced. National conditions and factors that encourage or impede inquiry will be discussed. 
In one effort to promote science education reform in Europe, teams from five-teacher training institutions (University of Sunderland-United Kingdom, University of Vienna-Austria, Palacky University-Czech Republic, Constantine the Philosopher University Nitra-Slovakia, and University of Palermo-Italy) came together to develop new math and science lessons that modeled exceptional instruction. The goal of Project MOTIVATE ME in Math and Science was to address the shortage of students entering teacher training in math and science by the development of motivational materials using appropriate pedagogical methods (Ulovec et al, 2007). As part of the project common definitions of frequently used pedagogical methods were developed. The definition of inquiry is listed below.

Inquiry based learning describes a range of philosophical, curricular and pedagogical approaches to teaching. Its core premises include the requirement that learning should be based around student questions. Pedagogy and curriculum requires students to solve problems requiring a holistic range of skills. Teachers use their knowledge to guide student inquiry. The inquiry method starts with summarizing current knowledge pertaining to a topic. Next, questions are formulated to focus the inquiry. Working together and individually, students discover solutions via various methods. The inquiry process invites students to experience the world's richness, empower them to ask their own questions, seek their own answers and challenges them to understand complexities (p. 18).

The definition is very broad covering mostly curriculum but also suggesting instructional practice. It was developed by the five teams each developing a list of common pedagogical methods in their national contexts and outlining their definition of those methods. The outlines were discussed and modified at a group meeting. The focus is on the inquiry process and the necessary skills needed for scientific inquiry. This particular definition does not address the nature of science. The goal of developing this definition was to facilitate communication among the project participants and their national contexts, so a broad definition might be a reasonable place to begin. The definition might evolve as the groups continue to cooperate and develop instructional materials.

Below are more detailed discussions of the national contexts in two of the countries (United Kingdom and Czech Republic) and the United States. The American author was a guest at the group meeting where the definitions were developed.

\section{National Context}

\section{United Kingdom}

Since 1989 in England there has been a national curriculum in science that has dominated the teaching of science in schools. The national curriculum defines the content to be taught, though this has undergone significant review since 1989 with the latest review being implemented in 2008, but has much less to say about the method(s) of instruction. Throughout the period the teaching and learning of scientific processes, as a component of scientific enquiry, has been present and has been given greater emphasis with time. The teaching of scientific enquiry emphasized in the curriculum would be categorized by Abd-El-Khalick (2004) as 'Inquiry as ends', i.e. scientific inquiry as a learning outcome for pupils, rather than 'Inquiry as a means', i.e. inquiry as an instructional approach. This paper therefore concentrates on reporting how scientific inquiry as a learning outcome has developed, particularly since 2000, in the English national curriculum. 
We begin with an overview of the status of scientific inquiry in the curriculum after the reforms of 2000. We proceed to include critical commentary from academic and inspectorial sources of the deficiencies in that version, and detail the changes of 2006 and 2008, which led to programs addressing scientific enquiry becoming part of a study of How Science Works. This change led to a much greater emphasis on pupils learning about the nature of science as a means of developing their scientific literacy. We will include some guidance on the availability of curriculum learning resources in these areas, and in so doing return to the theme the curriculum gives less emphasis to - how much inquiry based learning is included as an instructional method in teaching and learning about scientific enquiry.

In 2000 the curriculum defined its programs of study in terms of four attainment targets. Three of these, Life Processes and Living Things, Materials and their Properties, and Physical Processes, could be described as the content of biology, chemistry and physics, though they weren't named as such. The first attainment target was named "Scientific Inquiry," and was sub-divided as follows:

\begin{tabular}{|l|}
\hline Scientific Inquiry \\
Ideas and evidence in science \\
Investigative skills \\
- Planning \\
- Obtaining and presenting evidence \\
- Considering evidence \\
- Evaluating \\
\hline
\end{tabular}

The emphasis here is on investigative skills that are detailed as including turning ideas into a form that can be investigated scientifically, deciding on data collection, using equipment, making observations and measurements, judging uncertainty, using graphs to explain patterns, drawing conclusions and interpreting, evaluating outcomes and refining investigations. There is reference to scientific ideas, their presentation and dissemination. As well scientific enquiry includes scientific controversy, contexts in which science is carried out and the power and limitations of science. In terms of advice on how this target should be taught, the curriculum states "teaching should ensure that scientific enquiry is taught through contexts taken from the sections on life processes and living things, materials and their properties and physical processes." This advice tends to make the teaching of the content targets explicit, and the scientific inquiry target less clear - something that will permeate the teaching of the content rather than a selfcontained target. This is understandable in the sense that process skills in science may require context to rationalize them, but given the additional pressures of curriculum overload, assessment, teacher expertise and others, makes the status of scientific inquiry within the curriculum less clear than content based targets.

Millar (1998) had already given a critique of practical work in science. He identified two epistemological difficulties with the learning of scientific inquiry. He identified the false assumption that collection of data is a straightforward, common sense activity, and maintained that this aspect of investigation requires a choice of what data to collect which is based on prior ideas held about the matter under investigation. Secondly, he disputed that explanations will 'emerge' from observation. He referred to historical studies of scientific ideas and commented on the complexity of the process by which explanations arise from observations, noting that the explanation is an intellectual creation relying on much more than gathered observations. The 2000 curriculum was seen as being lacking in material to address these points. The approach was rather formulaic, teaching the process skills in the context of science content but not addressing the rationale of practicing these skills. 
Ofsted, the government inspectorial body, had also issued critical advice about the status of experimental and investigative science in schools at Key Stage 3 (KS3) aimed at children aged 11-14. It stated in 2000 that it was mainly used as an assessment activity and had not become an integral part of science teaching, and that it was often bolted on to the rest of the curriculum. It noted that planning and considering the strength of evidence was often neglected in practical work. In introducing the scientific inquiry target in 2000, the curriculum agency may have given some consideration to these academic and inspectorial comments, but the outcome was still open to the criticism that inquiry was bolted on and did not explicitly address the rationale for science adopting skills as part of a wider method of enquiry.

In short there was a call for the science curriculum to include an explicit section on the nature of science, which would include investigative skills and the treatment of evidence, but within a framework of scientific method which had to consider scientists and the context in which they work, and to consider different scientific ideas setting the rationale for the methods used. Sang (2002) summed this up in the introduction to an Association for Science Education (ASE) publication on the teaching of scientific inquiry. He stated, "young people should have a clearer grasp of the nature of science and how scientists work. They need to be able to look at scientific evidence and assess for themselves how strongly it supports the ideas that are being developed from it. They can learn to do this by examining current and past controversies involving science, and by developing their own skills of inquiry." The consensus in the science education community was that this element of the curriculum should be seen as a core requirement so that all pupils would have enhanced scientific literacy by studying this core. Programs for those pupils that wished to continue studying specialist science subjects to a higher level could be developed to augment this core and satisfy their needs, and the needs of employers and higher education institutions.

In 2006 the Qualification and Curriculum Agency (QCA) published a revised programs of study for Key Stage 4 (KS4) science, and in 2008 it has done the same for KS3. The KS4 programs were greatly slimmed down from the previous version, and the major emphasis was given to a study of How Science Works. The sections detailed are shown below:

\author{
How Science Works \\ Data, evidence, theories and explanations \\ Practical and enquiry skills \\ Communication skills \\ Applications and implications of science
}

There are contrasts immediately visible compared with the equivalent sections for the 2000 curriculum, but this contrast is more clearly seen from the explanatory notes published for the 2006 programs of study. These state:

During KS4, pupils learn about the way science and scientists work within society. They consider the relationships between data, evidence, theories and explanations and develop their practical, problem -solving and enquiry skills, working individually and in groups. They evaluate enquiry methods and conclusions both qualitatively and quantitatively, and communicate their ideas with clarity and precision. All pupils develop their ability to relate their understanding of science to their own and others' decisions about lifestyles, and to scientific and technological developments in society. 
As well teachers are told to ensure that the knowledge, skills and understanding of how science works are integrated into the teaching of what is labeled the Breadth of Study - this is a much-reduced set of topics from the biological, chemical and physical sciences. Certainly, in intent at least, the proportion of time spent on the nature of science, scientific literacy and scientific inquiry compared with that spent on content has increased.

The 2008 revised KS3 programs of study sought to underpin the changes that had been introduced for KS4. Extracts from an included statement on the importance of science give a flavor of the emphasis:

- The study of science fires pupils' curiosity about phenomena in the world around them.

- It links direct practical experience with scientific ideas.

- Pupils learn how knowledge and understanding in science are rooted in evidence.

- Pupils discover how scientific ideas contribute to technological change.

- Pupils trace the development of science world-wide and recognize its cultural significance.

- Pupils learn to question and discuss issues that may affect their own lives, the direction of societies and the future of the world.

These changes to the science curriculum in secondary schools in England are significant in their aims. If implemented in the spirit of these aims it would lead to a curriculum that concentrates on the nature of science, and its links with scientific inquiry, and scientific literacy as the prime targeted outcomes, rather than knowledge and understanding of scientific content. Like many reforms though, the reality may differ from this rhetoric.

Monk (2006) points out that the implementation of any new program of study depends on teachers interpreting it, and then rewriting their schemes of work to incorporate its spirit and content. In this case he argues that what happens will depend heavily on teachers' views of the nature of science and how science works. Williams (2006) points out a need for greater guidance on what is meant by How Science Works.

He contrasts the methods of Bacon, Popper and Khun, and argues that these are so diverse and to some extent too abstract for a school curriculum, that there must be a greater definition of the meaning from the curriculum agencies. There will be a need for professional development for teachers, many of whom will have learnt little in their formal education about the nature of science, and few of whom will have direct personal experience of working as a scientist. Provision of resource materials will be essential so that teachers are able to rely on made to measure activities directed at pupils learning about scientific inquiry.

Indeed resource provision to address some parts of the new program is already in place. In 2005 the Department for Education and Skills (DfES) as part of a KS3 National Strategy sent all science departments in schools a CD entitled Moving Forward with Teaching Scientific Enquiry and Intervention. This resource as well as giving an overview, took each part of the enquiry part of the program and provided ideas to help pupils get better, and provided a listing of resources. ASE produced written resources such as Teaching Secondary Scientific Enquiry that includes specific investigations and teaching suggestions for each part of the enquiry process. It also produced Developing Understanding in Scientific Enquiry that addresses the different enquiry methods, and then goes on, using a $\mathrm{CD}$, to give classroom examples dealing with each of these.

Projects such as ASE and King's Science Investigations in Schools Project (AKSIS) and Cognitive Acceleration through Science Education Project (CASE) have a well-established and commended set of resources for teaching scientific inquiry. Although there is less material available for the wider remits of the 2006 and 2008 programs, resources from Science and Technology in Society (SATIS), Concept Cartoons in Science Education (CONCISE) and SciQ 
do address both the nature of science and scientific literacy. These are just a small fraction of the resources available so it is unlikely that the new programs will suffer from a paucity of good quality resource material.

It is the case though that the national curriculum steers away from providing a prescriptive method of instruction for schools to follow. It is argued that having provided the curriculum content itself, which is statutory, advice on implementation and some resource material, that the schools themselves should be allowed to adjust their provision taking into account their pupils, their teachers, their ethos and their resource base. The KS3 program does include a section headed Curriculum Opportunities, and this includes as one item, "pupils should pursue an independent enquiry into an aspect of science of personal interest." It could be argued that this necessitates the "inquiry as a means" category of instruction that Abd-El-Khalick (2004) discusses, but this is a minor requirement of the whole curriculum. Monk argues that by insisting pupils work in groups, firstly to answer the question "What is happening?" and then separately and separated by class presentations and discussions, "Why does that happen?" the nature of science learning activities can become more discursive, more open and more investigational. This though is a suggestion from one commentator, and the reality of its implementation is not established.

In conclusion the revisions to the program of study in 2006 and 2008 have made the study of the nature of science, and within it scientific enquiry, more explicit than it has been in national curriculum science in England. There has been a move to make the whole of scientific inquiry taught more directly than assuming that it will be learnt by studying elements of science content. It is premature to make a judgment on the success of its implementation, and the move does not have wholehearted support with comments about 'dumbing down' from a variety of sources. However, there are grounds for optimism. In his inaugural professorial address at the Royal Society, London on 23 June 2008, Professor Derek Bell, Chief Executive of ASE, quoted Ofsted evidence as follows:

Schools that focus clearly on how science works - the practical and investigational aspects rather than only the theoretical elements - are the most successful at teaching the subject.

Perhaps this pressure from the organization that inspects all school science will be effective in ensuring the methods of scientific enquiry are enmeshed in an integrated and contextual way into the teaching and learning of science in English schools.

\section{United States}

The history of inquiry in the K-12 US science curriculum has roots in John Dewey's progressive reforms in 1910 but the concept did not gain momentum until the launch of Sputnik in 1957 (Barrow, 2006). Despite this long history of advocacy and research, there still does not exist an operational definition of inquiry teaching and learning. Anderson (2002) states, "Since the NSES contains no precise operational definition of inquiry teaching - though it does contain some specific teaching examples - many and varied images of images of inquiry teaching can be expected among its readers" (p. 3). This variety of images presents a challenge when looking for trends and attempting to synthesize the research on inquiry teaching. Within the United States, inquiry can be seen as a type of learning, an instruction approach or as an instructional outcome.

The two dominate reforms documents in the United States have been the American Association for the Advancement off Science (AAAS) Science for all Americans (Rutherford, 
1989) and the National Research Council's National science education standards (NSES) (1996). NRC (2000) released Inquiry and the National Science Education Standards and AAAS released both Benchmarks for Science Literacy (1993) and Atlas of Scientific Literacy (2001) to further identify what students should learn. Science for all Americans defines what all students should know and be able to do when they graduate $12^{\text {th }}$ grade. Included in the goal of scientific literacy is knowledge of the processes that create scientific knowledge. Inquiry is considered a content topic with the following recommendations: start with a question about nature, engage students actively, concentrate on the collection and use of evidence, provide historical perspective, communication using clear expectation, team approach, and link knowledge with how if it found out.

The AAAS places emphasis on understanding about inquiry where as the NSES place equal emphasis on doing inquiry and knowing about inquiry. The NSES emphasis teaching of science through inquiry as a means to achieve scientific literacy can be seen in quote;

Scientific inquiry refers to the diverse ways in which scientist study the natural world and propose explanations based on the evidence derived from their work. Inquiry also refers to the activities of students in which they develop knowledge and understanding of scientific ideas, as well as an understanding of how scientists study the natural world (p. 23).

The NSES also uses inquiry to refer to an active learning process, "something that students do, not something that is done to them" (p. 2). The belief is that inquiry learning should reflect the nature of scientific inquiry. Bybee (2002) links how students learn and scientific inquiry providing a rationale for teaching using inquiry instructional methods when he comments; "I will note here that this process of natural inquiry is quite similar to the more formal processes of scientific inquiry" (p. 31). Anderson (2002) suggests that the NSES "some would argue, for example, that all learning is inquiry learning, i.e., it is an active mental process that demands the active participation of the learner. The argument is essentially the same as the argument of those who say that all learning is "constructivist"” (p. 2).

One of the earlier reports on science teaching as practiced in schools was the case study research of Stake and Easley (1978). They were investigating the implementation of National Science Foundation supported curriculum intended to foster inquiry teaching. Two reasons were cited as the cause for the inquiry curriculum not being implemented as intended; widespread philosophic persuasion in favor of a textbook approach and frustration and difficult problems when implementing inquiry. Anderson (2002) notes that there is little indication that typical school practice has not changed significantly since Stake and Easley's report.

While inquiry may be advocated in key local, national, and global reform documents, what is actually implemented in the classroom may not follow the national reform recommendations. In one recent study, inquiry as content was observed in $15 \%$ of the elementary classrooms and only $2 \%$ of the grade 9-12 classrooms (Weiss, Pasley, Smith, Banilower, and Heck, 2003). Science educators are urging the inclusion of inquiry but there is little impact in the K12 schools.

While national science standards exist, these are not a national curriculum. Each state determines its own standards that may or may not follow the national models. In South Carolina, the secondary science standards adopted in 2005 include specific inquiry standards and indicators for each science discipline. The Fordham Institute evaluation of 49 state science standards awarded the South Carolina standards with one of only five letter grades of an "A" (Fordham, 2005). The standard and indicators for science are shown in chart 1. The indicators reflect science skills such as using science instruments and organizing data. Indicators concerning the nature of science are absent. Among the remaining 10 standards in physics, there are 
no indicators that address the nature of science, history of science, or societal aspects of science as called for in the national science standards.

\title{
Chart 1: South Carolina Inquiry Standards for Secondary School Physics
}

\author{
Standard P-1: \\ The student will demonstrate an understanding of how mathematical analy- \\ sis, scientific inquiry, and technological design can be used appropriately to \\ pose questions, seek answers, and develop solutions.
}

\section{Indicators}

P-1.1 Apply established rules for significant digits, both in reading scientific instruments and in calculating derived quantities from measurement.

P-1.2 Use appropriate laboratory apparatuses, technology and techniques safely and accurately when conducting a scientific investigation.

P-1.3 Use scientific instruments to record measurement data in appropriate metric units that reflect the precision and accuracy of the instrument.

P-1.4 Design and evaluate the design of a scientific investigation including an appropriate hypothesis, independent and dependent variables and appropriate methods of control.

P-1.5 Collect, organize, and interpret the data from a scientific investigation using mathematics (calculations in scientific notation, formulas and dimensional analysis), graphs, tables, models, diagrams, and/or technology.

P-1.6 Evaluate the results of a controlled scientific investigation in terms of whether it refutes or verifies the hypothesis.

P-1.7 Evaluate conclusions based on qualitative and quantitative data, including the impact of sources of error (parallax, instrument malfunction, or human error) on experimental results.

P-1.8 Evaluate a technological design or product based on designated criteria.

P-1.9 Communicate and defend a scientific argument or conclusion.

The South Carolina standards reflect a common inconsistency between the national recommendations and local curriculum. The focus on the inquiry indicators in South Carolina is on skills necessary for inquiry but does not address an understanding about inquiry or the nature of science. Lederman commented; "To my mind, a stress on understanding about inquiry is clearly more consistent with the goal of scientific literacy than the more perennial stress on doing inquiry" (Abd-El Khalick, 2004, p. 402). The South Carolina standards perhaps provide an example of Lederman's concern that by focusing on the individual process skills without going further to discuss the nature of science, we are actually not addressing true scientific literacy. Research suggests that explicit instruction about the nature of science is necessary and that students do not develop that knowledge by just engaging in inquiries. While the standards encourage teachers to use inquiry instructional approaches, the lack of standards about the nature of science will result in teachers continuing to not teach about the nature of science.

In addition to the narrow definition of inquiry found in the state standards, there is also the issue of science teachers' skills and willingness to teach inquiry or use inquiry methods. Lotter, Harwood and Booner (2007) found that teachers' conception of science, their students' abilities, effective teaching practices and the purpose of education influenced the type and amount of inquiry instruction in the high school classrooms. For example, teachers who did not think their students were college bound typically did not teach inquiry. Also, a teacher would less likely use inquiry if they felt they were expected to teach passive students and cover the textbook to prepare students for college. Wallace and Kang (2004) also found that teachers' beliefs about science learning were linked to beliefs about laboratory and inquiry implementa- 
tion. A teacher who used inquiry-based labs also believed that successful science teaching was enculturation into scientific practices. These studies suggest that teachers play a significant role in the implementation of inquiry in the high school science lab and a that professional development and preservice preparation needs to address the teachers' core beliefs and understanding about science, learning, and the job expectations.

\section{Czech Republic}

In accordance with the new principles of curricular politics, formulated in the National Program for the Development of Education in the Czech Republic (the so-called White Paper) and embodied in Act No. 561/2004Coll., On Preschool, Elementary, Secondary, Higher Vocational and Other Education (hereinafter only as the Education Act) a new system of curricular documents for the education of pupils between 3 and 19 years of age is being introduced into the educational system. Curricular documents are developed on two levels; state and school. In the system of curricular documents, the state level is represented by the National Education Program (NEP) and Framework Education Programs (FEPs). Whereas the NEP formulates the requirements for the education, which are applicable in initial education as a whole, the FEPs define the binding scope of education for its individual stages (for preschool, elementary, and secondary education). The school level is represented by School Education Programs (SEPs), on the basis of which education is implemented in individual schools. The SEP is created by each school according to the principles prescribed in the respective FEP. Both the Framework and School Education Programs are public documents, available to the teaching as well as lay public.

Framework Education Programs (FEP) are based on a new educational strategy which emphasizes key competencies, their interconnectedness with the educational content and application of the acquired knowledge and skills in real life (VUP 2007, p.6). The competencies build on the concept of lifelong learning and support the educational autonomy of schools and professional responsibility of the teachers for the outcomes of the educational process.

Educational content has been divided into eight educational areas in the FEP. Individual educational areas consist of one or more educational fields of similar educational content. One of these educational areas is so-called Man and Nature. This area is divided into the educational fields: Biology, Chemistry, Geography, and Physics. Characteristic of this educational area is following:

The main priority of each area of natural-science learning is to uncover the laws governing natural process by means of the methods of scientific research. Uncovering natural laws is rewarding in itself, as it satisfies the natural human curiosity to gain knowledge and understand what takes place beneath the surface of perceptible and often seemingly unrelated phenomena on the one hand and makes it possible to gain control over various natural objects and processes in order to be able to use them for further research as well as for various practical purposes on the other (FEP, p. 25).

Studying the state curricular material FEP, as well as the literature of didactics of physics, chemistry or biology, we cannot find the concept of inquiry. It is clear that the definition of the concept inquiry we cannot be found in the literature, but we can find many concepts that are connected or related with the inquiry there: hands-on experiments, problem solving, formulating of hypotheses, designing experiments, gathering and analyzing data, and drawing conclusions.

FEP (p. 26) recommends that "the pupil shall have the highest number of opportunities possible to master progressively the empirical as well as theoretical methods of natural science 
research selected, utilize them in the instruction along with the information on natural sciences, realize the importance of both for scientific knowledge, and particularly for its objectivity and veracity as well as for solving the problems which Man encounters when examining nature."

The instruction in this educational area is guiding the pupil towards (FPS, p. 26):

- Formulating a natural-science problem, seeking an answer to it and possibly also specifying or correcting the solution to this problem;

- Carrying out systematic and objective observations, measurements and experiments according to individual or team plans or projects, and towards processing and interpreting the data obtained and seeking connections between them;

- Predicting the course of the natural processes studied based on the knowledge of general natural-science laws and specific conditions;

- Predicting possible impact of practical human activities on the natural environment.

This curricular material (FPS) provides framework for incorporating various aspects of inquiry, otherwise the concept of inquiry is not implemented and defined directly.

In the Czech Republic science instruction is still traditional. Teachers' knowledge about inquiry is necessary before its implementation in classroom instruction. Teachers need to be well versed in scientific inquiry as a teaching approach and need to develop pedagogical skills necessary to teach effectively about and for inquiry. Teachers must value knowledge and skills about inquiry as important. Having the knowledge and skills to teach inquiry is a little of use if science teachers do not value the importance of these instructional outcomes. Such importance is not intuitively obvious to teachers and students. Curricular materials should enhance the valuing of the inquiry approach to science teaching. Teachers should recognize from their practice that this approach brings deeper understanding of the nature of science, better results of students and their higher motivation and interest to study science.

\section{Discussion}

All three countries show changes and modifications of their standards and curriculums as it relates to inquiry perhaps demonstrating the influence of the global discussion within the science education community. Each nation has a different approach to the implementation of their respective science curriculums. The ability of those approaches to change teacher behavior and instructional methods remains to be determined. Anderson (1996) identified three dimensions that described the typical barriers and dilemmas faced by schools and teachers implementing new approaches to science instruction; technical dimension, political dimension, and the cultural dimension. The technical dimension included the ability to teach constructively, degree of commitments to textbooks, difficulties of group work, challenge of new active student role rather than passive, and inadequate in-service professional development. Political dimension at the school level was characterized by short-term commitment to in-service professional development, parental resistance, lack of resources, and conflicts among teachers. The most important dimension was cultural dilemmas. Beliefs and values centered on the use of the textbook, views of assessment, and a commitment to coverage were all part of the cultural dilemma. In order for reform to take place, including use of inquiry approaches, all three dimensions must be addressed.

The US science education community has long advocated inquiry-teaching methods and has a curriculum focused on inquiry skills while the UK has recently modified its curriculum goals to include more on the nature of science. Inquiry is not implemented directly in the Czech curricular materials although what is included focuses on solving problems and the scientific method. While each of the definitions of inquiry varies with the degree of emphasis on inquiry 
skills and the inclusion of the nature of science, all three nations share difficult in over coming the cultural beliefs of teachers and school leaders when it comes to classroom instruction.

The Project MOTIVATE is one example of an attempt by different nations to overcome technical barriers. Modeling and providing curriculum units to teachers is one method to support teacher-training institutions and classrooms teachers. The participating universities all include secondary school teachers as part of their teams. The collaboration needs to continue and to address cultural barriers that may inhibit science teachers from embracing inquiry curriculum and instruction. One participating teacher challenged what they perceived as the inference that teaching the science inquiry content without using an inquiry approach is incomplete. In addition to curriculum materials, future collaboration needs to help facilitate changing science teacher culture by engaging them in the discourse.

Much of the discussion in this paper on the definitions of inquiry emerged from within the larger political systems but ultimately influence the schools' and teachers' political dimension. The reform documents in each national context address inquiry to various degrees with the UK and US having the most detailed and structured standards. The United States does not have a national curriculum but each state, as a result of a federal mandate, does have detailed standards. In the case of the South Carolina science standards, they have inquiry embedded within the secondary science disciplines such as physics. While the South Carolina standards, reflecting the standards movement across the United States, provides specific detail with the intent of holding teachers accountable. England, like the United State's approach, has a national curriculum that recently increased the focus on the nature of science. Both are essentially a top-down approach. The Czech Republic has a different approach providing more broad guidelines and allowing the individual schools to develop their own curriculum to meet the broad guidelines. The new Czech reforms reflect a move toward providing schools with more autonomy and freedom to meet the broad goals. Science teachers in all three nations have different external political forces influencing the implementation of inquiry teaching and it remains to be seen if having the loci of control located in the schools or in state/federal agencies is more successful in changing teacher practice.

All three countries have initiated changes to curriculum and their infrastructure to implement and sustain reform. Programs such as Project MOTIVATE help address the technical dimensions, providing teacher-training programs with resources that will help them change teacher practices. Each of the participants adapts the materials to their local setting and addresses the cultural realities. All three settings discussed the difficulty of translating the defined curriculum into classroom practice reflecting the significance of the cultural dimension. Tobin and McRobbie (1996) in their work on cultural myths, concluded "If the reforms are to proceed as recommended it will be necessary for conversations about teaching and learning to become a more visible component of the lives of all stakeholders and for a majority to understand the need for change, advocate reform, reconceptualize their goals and associate roles, and support others in their efforts to enhance the learning of science" (p. 239). The dialog and collaboration concerning inquiry must continue and expand including more secondary science classroom teachers in order for meaningful change to take place within each nation's classrooms. 


\section{References}

Abd-El-Khalick, F., BouJaoude, S., Duschl, R., Lederman, N.G., Mamlock-Naaman, R., Hofstein, A., Niaz, M., Treagust, D., \& Tuan, H, (2004). Inquiry in science education: International perspective. Science Education, 88: 397-419.

Abd-El-Khalick, F., BouJaoude, S., Hofstein, A., Lederman, N.G., Mamlock, R., Niaz, M., Treagust, D., \& Tuan, H. (2001 March). Inquiry in science education: International perspectives. In. An ICASE symposium conducted at the annual meeting of the National Association for Research in Science Teaching. St. Louis, MO.

American Association for the Advancement of Science. (1993). Benchmarks for scientific literacy. Washington DC: Author.

American Association for the Advancement of Science. (2001). Atlas of scientific literacy. Washington DC: Author.

American Association for the Advancement of Science. (1990). Science for All Americans. New York: Oxford University Press.

Anderson, R. D. (2002). Reforming science teaching: What research says about inquiry? Journal of Science Teacher Education, 13 (1): 1-12.

Anderson, R. D. (1996). Study of curriculum reform. Washington DC: US Government Printing Office.

Barrow, L. H. (2006). A brief history of inquiry: From Dewey to Standards. Journal of Science Teacher Education, 17: 265-278.

Bell, D. (2009.) Engaging teachers, engaging pupils, engaging science: are we learning our lessons? School Science Review, 90 (330): 35-44.

Bybee, R. W. (2002). Scientific inquiry, student learning, and the science curriculum. In. Bybee, R.W. (ed), Learning science and the science of learning. Arlington Virginia: NSTA Press.

Framework Education Programme (FEP) for Secondary General Education. (2007). Praha: Výzkumný ústav pedagogický. ISBN 978-80-87000-23-6.

Gross, P.R. (2005). The State of State Science Standards 2005. Thomas B. Fordham Institute, Washington DC. On-line at http://www.edexcellence.net/doc/Science\%20Standards.FinalFinal.pdf

Lotter, C., Harwood, W.S., Bonner J. J., (2007). The influence of core teaching conceptions on teachers' use of inquiry teaching practices. Journal of Research in Science Teaching, 44 (9): pp. 1318-1347.

Millar, R. (1998). 'Rhetoric and Reality: What practical work in science is really for' in J. Wellington (ed.), Practical work in school science. London and New York: Routledge pp.16-31.

Monk, M. (2006). How science works: what do we do now? School Science Review, 88 (332), 119-121.

National Research Council. (1996). National science education standards. Washington DC: National Academy Press.

National Research Council. (2000). Inquiry and the national science education standards. Washington DC: National Academy Press.

Rutherford, F. J. \& Ahlgren, A. (1989). Science for all Americans: A Project 2061 report. Washington DC: American Association for the Advancement of Science.

Sang, D. and Wood-Robinson, V. (2002). Teaching Secondary Scientific Enquiry London: John Murray. 
South Carolina Science Academic Standards. (2005). Columbia, South Carolina: State Department of Education. Available online at http://ed.sc.gov/agency/Standards-andLearning/Academic-Standards/old/cso/standards/science/index.html.

Tobin, K., McRobbie, C. J. (1996). Cultural myths as constraints to the enacted science curriculum. Science Education, 80 (2): 223-241.

Ulovec, A., Čeretková, S., Hutton, N., Molnár, J., Spagnolo, F. (eds.) (2007). Motivating and Exciting Methods in Mathematics and Science: Glossary of terms. Olomouc CZ; Palacky University. Socrates-Comenius 2.1 \# 129572-CP-1-2006. ISBN 978-80-244-1830-8.

Wallace, C. S., Kang, N-H. (2004). An investigation of experienced secondary science teachers' beliefs about inquiry: An examination of competing belief sets. Journal of Research in Science Teaching, 41 (9): 936-960.

Weiss, I. R., Pasley, J. D., Smith, P.S., Banilower, E. R., \& Heck, D. J. (2003). Looking inside the classroom: A study of K-12 mathematics and science education in the United States. Chapel Hill, NC: Horizon Research.

Williams, J. (2006). Will the new GCSE really teach pupils how science works? Education in Science, 218, 14-15.

Williams, J. (2007). Do we know how science works? A brief history of the scientific method. School Science Review, 89 (327), 119-124.

Received 10 December 2010; accepted 15 February 2011

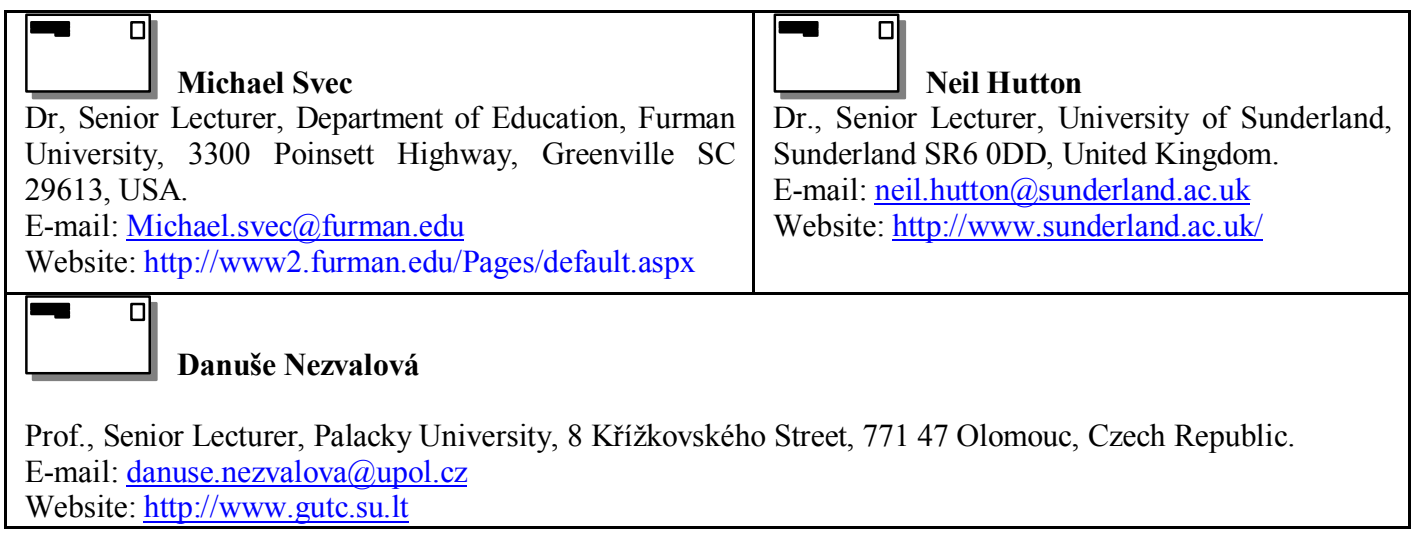

